\title{
PEMETAAN POLA PERGERAKAN PENANGKAPAN IKAN CAKALANG (Katsuwonus pelamis) DENGAN MENGGUNAKAN DATA SATELIT DAN PURSE SEINE DI SELAT MAKASSAR SELAMA JULI-OKTOBER 2018
}

\section{MAPPING OF SKIPJACK (Katsuwonus pelamis) FISHING MOVEMENT PATTERN USING SATELLITE AND PURSE SEINE DATA IN MAKASSAR STRAIT DURING JULY-OCTOBER 2018}

\author{
Ahmad Rezha Oktari ${ }^{1 *}$, Muhammad Ridwan ${ }^{2}$, Mukti Zainuddin ${ }^{1}$, dan Musbir $^{1}$ \\ ${ }^{1}$ Program Studi Pemanfaatan Sumberdaya Perikanan Fakultas Ilmu Kelautan \\ dan Perikanan Universitas Hasanuddin \\ ${ }^{2}$ Depatemen Agribisnis Perikanan, Politeknik Pertanian Negeri, Pangkep \\ *rezhaahmad40@gmail.com
}

Diterima (receive) : 04 Juli 2019; Disetujui (accepted) : 27 Agustus 2019

\begin{abstract}
ABSTRAK
Tujuan penelitian ini adalah untuk mengkaji dan memetakan pola pergerakan ikan Cakalang (Katsuwonus Pelamis) pada bulan Juli - Oktober 2018 dengan fishing base di Kabupaten Pinrang di Selat Makassar. Data yang digunakan yaitu data primer yang dikumpulkan dengan mengikuti operasi penangkapan purse seine dan dikombinasikan dengan data sekunder yaitu citra satelit suhu permukaan laut dan klorofil-a yang diperoleh dari satelit Aqua modis sesuai dengan waktu penelitian. Metode yang digunakan dalam penelitian ini adalah metode survey dimana data sampling dianalisis dengan menggunakan analisis statistic General Additive Mode/ (GAM) yang menganalisis hasil tangkapan dan beberapa parameter oseanografi. Dari hasil tersebut kemudian dilakukan analisis dengan tehnik spasial analisis pada sistem informasi geografis (SIG) menggunakan perangkat lunak ArcGis 10.2 sehingga didapatkan pola pergerakan ikan cakalang di Perairan Selat Makassar. Hasil penelitian menunjukkan pola pergerakan ikan cakalang pada bulan Juli sampai Oktober secara signifikan dipengaruhi oleh konsentrasi Klorofil-a. Pola pergerakan ikan cakalang di Perairan Selat Makassar yaitu pada bulan Juli - Agustus 2018 berada di Perairan Pare pare - Barru, Sulawesi selatan dan bulan September gerombolan ikan bergerak ke arah barat lepas pantai. Selanjutnya pada bulan Oktober konsentrasi ikan cenderung bergerak terus ke arah barat mendekati perairan pantai Kotabaru, Kalimantan Selatan. Diduga kuat pola pergerakan ikan cakalang terkait dengan pola distribusi makanan ikan / nutrient yang diindikasikan oleh kondisi klorofil-a.
\end{abstract}

Kata Kunci: Purse seine, Cakalang, Selat Makassar, GAM, data satelit, Pola Pergerakan Ikan

\begin{abstract}
The purpose of this study was to examine and map the movement patterns of skipjack tuna (Katsuwonus Pelamis) in July - October 2018 in Makassar Strait. The data used are primary data collected by following purse seine fishing operations and combined with secondary data namely satellite images of sea surface temperature and chlorophyll-a derived from Aqua/MODIS satellite according to the time of the study. The method used was a survey method where the sampling data was analyzed using statistical analysis of the Generalized Additive Model (GAM) which assessed the catch and both the oceanographic parameters. Spatial techniques was then performed on a geographic information system (GIS) to obtain skipjack movement patterns in the Makassar Strait. The results showed that the movement pattern of skipjack from July to October was
\end{abstract}


significantly influenced by the concentration of Chlorophyll-a. The pattern of movement of skipjack in the Makassar Strait was that in July - August 2018 occurred in the Pare Pare - Barru waters, South Sulawesi and in September the fish moved west off the coast. Furthermore, in October the concentration of fish tended to move further west toward the coastal waters of Kotabaru, South Kalimantan. It suggests that the movement pattern of the fish is related to the distribution pattern of fish food / nutrient which is indicated by the condition of chlorophyll-a.

Keywords: Purse seiner, Skipjack, Makassar Strait, GAM, movement pattern, satellite data

\section{PENDAHULUAN}

Selat Makassar merupakan salah satu perairan yang relatif lebih subur di Indonesia (Gordon, 2005). Penyuburan perairan Selat Makassar terjadi sepanjang tahun baik pada musim barat maupun pada musim timur. Pada musim barat penyuburan terjadi karena adanya run off dari daratan Kalimantan maupun Sulawesi dalam jumlah besar akibat curah hujan yang cukup tinggi, sedangkan pada musim timur terjadi penaikan massa air (upwelling) di beberapa lokasi di Selat Makassar akibat adanya pertemuan massa air dari Samudera Pasifik dengan massa air Laut Jawa dan Laut Flores (Afdal \& Riyono, 2004, Inaku, 20111).

Salah satu sumberdaya ikan di Selat Makassar yang potensinya cukup besar adalah ikan cakalang. Adapun data produksi ikan cakalang yang berasal dari 7 kabupaten dan kota yang ada di pesisir Selat Makassar dalam 6 tahun terakhir menunjukkan peningkatan produksi rata-rata 3,47 \% dari 3.580,5 ton pada tahun 2008 menjadi 4.201,7 ton pada tahun 2012 (Amir \& Mallawa, 2015).
Ada beberapa faktor yang berpengaruh terhadap keberhasilan kegiatan penangkapan ikan cakalang diantaranya suhu dan klorofil-a. Suhu adalah suatu besaran fisika yang menyatakan banyaknya bahang (heat) yang terkandung dalam suatu benda. Secara alamiah sumber bahang utama adalah sinar matahari. Pada umumnya perairan yang banyak menerima bahang dari matahari adalah daerah yang terletak pada lintang rendah dan akan semakin berkurang bila letaknya semakin mendekati kutub (Inaku, 2011). Suhu permukaan laut dapat digunakan sebagai salah satu cara untuk menduga keberadaan organisme di suatu perairan, khususnya ikan. Hal tersebut disebabkan karena sebagian besar organisme bersifat poikilotermik dimana suhu tubuh dari organisme hampir sama dengan suhu yang ada disekitarnya. Selain itu, pengaruh suhu secara langsung terhadap kehidupan di laut berpengaruh pada laju fotosintesis tumbuhan dan proses fisiologi hewan (Edmondri, 1999).

Di lautan, klorofil-a identik dengan adanya phytoplankton yang merupakan 
sumber makanan primer bagi organisme laut terutama ikan. Pengukuran kandungan klorofil-a merupakan salah satu alat pengukur kesuburan suatu perairan yang dinyatakan dalam bentuk produktivitas primer. Klorofil-a adalah suatu pigmen aktif dalam sel tumbuhan yang mempunyai peranan penting dalam berlangsungnya proses fotosintesis di perairan yang dapat digunakan sebagai indikator banyak atau tidaknya ikan di suatu wilayah dari gambaran siklus rantai makanan yang terjadi di lautan. Konsentrasi klorofil-a pada suatu perairan sangat tergantung pada ketersediaan nutrien dan intensitass cahaya matahari. Bila nutrien dan intensitas matahari cukup tersedia, maka konsentrasi klorofil-a akan tinggi dan sebaliknya (Effendi et al.,2012).

Berdasarkan informasi diatas, maka dianggap perlu melakukan penelitian tentang pemetaan terhadap pola distribusi ikan Cakalang (Katsuwonus pelamis) yang terdapat pada perairan Selat Makassar. Diharapkan dari hasil penelitian ini dapat menjadi informasi tentang bagaimana pola pergerakan ikan Cakalang (Katsuwonus Pelamis) yang terjadi di daerah selat Makassar. Serta dapat dimanfaatkan sebagai penentuan lokasi penangkapan ikan Cakalang (Katsuwonus Pelamis) yang efektif.

\section{METODOLOGI PENELITIAN}

\section{Waktu dan Tempat}

Penelitian ini telah dilaksanakan pada bulan Juli - Oktober 2018. Dilakukan pada wilayah perairan Selat Makassar dengan fishing base di Kabupaten Pinrang.

\section{Metode Pengumpulan Data}

Pengumpulan data pada penelitian ini dilakukan secara in-situ (lapangan) dan ex-situ (citra suhu permukaan laut dan klorofil-a satelit Terra/Aqua modis).

1. Pengumpulan data in-situ

Prosedur pengabilan data in-situ meliputi:

a. Persiapan, pada tahap ini dilakukan studi literatur, observasi lapangan, konsultasi dengan beberapa pihak yang ahli dan mempersiapkan perlengkapan yang dibutuhkan dalam melakukan penelitian

b. Penentuan titik koordinat menggunakan GPS (Global positioning system). Titik tersebut berupa titik fishing base dan fishing ground.

c. Melakukan pengukuran suhu permukaan laut secara langsung dengan menggunakan thermometer digital pada setiap penangkapan ikan

d. Melakukan pengukuran kandungan klorofil dengan cara mengambil sampel air laut dan memasukkannya 
kedalam botol sampel dengan volume $1.500 \mathrm{ml}$ yang telah ditutupi dengan lakban hitam kemudian disimpan dalam coolbox yang tertutup rapat dengan tujuan agar cahaya matahari tidak masuk dan menghentikan laju metabolisme klorofil-a.

e. Melakukan penghitungan jumlah hasil tangkapan tiap hauling (per ekor) dan melakukan pengukuran panjang ikan sampel.

f. Data hasil tangkapan meliputi total hasil tangkapan per ekor pada setiap pengoperasian dan jumlah ikan setiap trip nya.

2. Pengumpulan data dengan metode ex-situ

a. Pengumpulan data citra suhu permukaan air laut

Data citra suhu permukaan laut diperoleh dengan bantuan satelit terra/modis dengan resolusi 4 km x 4 km (Pixel). Data citra yang dikumpulkan pada penelitian ini yaitu pada bulan antara Juli sampai Oktober 2018.

b. Data citra klorofil-a

Data citra klorofil-a diperoleh dengan bantuan satelit aqua/modis degan resolusi 4 $\mathrm{km} \times 4 \mathrm{~km}$ (pixe).

Data citra klorofil yang dikumpulkan yaitu pada citra klorofil pada bulan Juli sampai Oktober 2018

\section{Analisis Data}

1. Citra suhu permukaan laut

Citra suhu satelit Terra Modis sea surface temperature $(11 \mu$ day time $)$ yang dianalisis merupakan data bulanan pada bulan Juli sampai Oktober 2018. Hal ini dilakukan untuk melihat bagaimana anomaly suhu permukaan laut pada bulan itu.

2. Citra Sebaran klorofil-a

Untuk mengetahui sebaran klorofil pada bulan Juli sampai Oktober 2018, data yang dipakai adalah citra satelit Aqua MODIS Chlorophyll concentration, dari data tersebut, kita dapat mengetahui bagaimana sebaran klorofil pada bulan tersebut pada setiap bulannya.

3. General Additive Model (GAM)

Dari data parameter oseanografi yang didapatkan akan dilakukan pengujian lanjutan dengan metode GAM. Pemilihan model GAM ini dilakukan untuk memperkirakan bagaimana hubungan variable dengan kelimpahan ikan cakalang (Zainuddin et al., 2013). Sebelum dilakukan analisis GAM, terlebih dahulu dilakukan eksplorasi terhadap seluruh data set. Tujuannya yaitu untuk mengidentifikasi adanya data pencilan dan kolinearitas antar setiap variable penjelas. Pustaka yang terdapat pada program $\mathrm{R}$ merupakan pembentukan dari model GAM. Ikan cakalang hasil tangkapan adalah sebagai 
variable $y$, sedangkan variable-variable oseanografi yang telah terseleksi dalam proses eksplorasi data adalah sebagai variable x (Wibawa et al., 2012).

\section{HASIL DAN PEMBAHASAN}

\section{Hubungan Faktor Oseanografi dengan Hasil Tangkapan}

\section{General Additive Model (GAM)}

Analisis menggunakan metode GAM dari software R (versi 3.4.2) ini dilakukan untuk memperkirakan sebaran kelimpahan ikan cakalang. GAM memiliki kemampuan untuk menjelaskan pengaruh dari setiap variabel prediktor yaitu suhu permukaan laut dan klorofil-a dengan variabel respons yaitu hasil tangkapan.

Berdasarkan analisis menggunakan metode GAM dari software $\mathrm{R}$ (versi 3.4.2), maka didapatkan hasil sebagai berikut. Dilihat pada Tabel 1.

Tabel 1. Analisis Data Tangkapan Terhadap Parameter Oseanografi

\begin{tabular}{ccccc}
\hline & Edf & Ref.df & $F$ & $p$-value \\
\hline$s(\mathrm{chl})$ & 3.989 & 4.780 & 13.389 & $3.08 \mathrm{e}-08$ *** \\
\hline $\mathrm{s}(\mathrm{spl})$ & 5.596 & 6.615 & 1.927 & 0.0785. \\
\hline
\end{tabular}

Berdasarkan hasil analisis nilai signifikan klorofil-a dan suhu permukaan laut menggunakan model GAM (Tabel 1) diperoleh nilai signifikansi klorofil-a terhadap hasil tangkapan yaitu $3,08 \mathrm{e}-08$ ***, hal ini menandakan bahwa klorofil-a memiliki siknifikansi yang sangat baik terhadap hasil tangkapan tangkapan. Dari data tersebut dapat disimpulkan bahwa klorofil-a memiliki

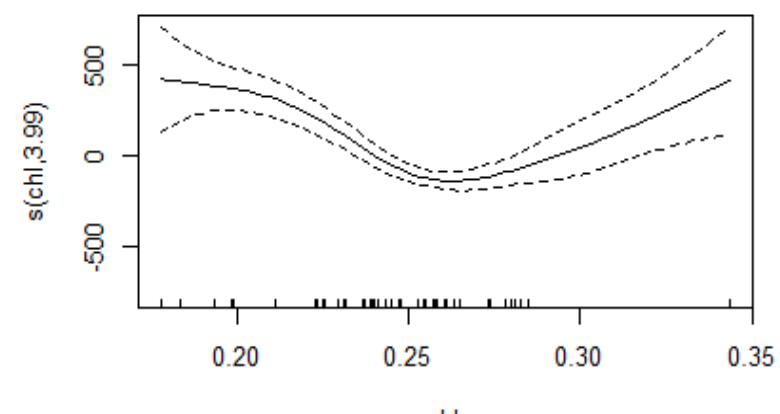

chl pengaruh nyata terhadap hasil tangkapan ikan cakalang pada Selat Makassar dibandingkan suhu permukaan laut. Hal ini dapat dikaitkan dengan penggunaan rumpon sebagai alat bantu penangkapan dan rantai makanan pada ikan. Akibatnya ikan berkumpul di lokasi rumpon dan menjadi target penangkapan ikan yang produktif.

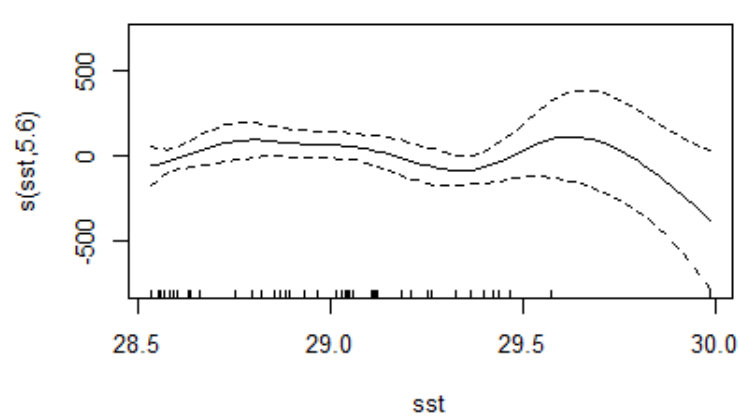


Gambar 1. Distribusi hasil tangkapan ikan cakalang (Juli-Oktober) di perairan Selat Makassar dengan parameter oceanografi

Berdasarkan distribusi hasil tangkapan dengan parameter oceanografi (Gambar 1) dapat dilihat pengaruh setiap parameter oseanografi terhadap hasil tangkapan ikan cakalang selama penelitian di perairan Selat Makassar. Sumbu X menunjukkan nilai dari tiap variabel yang dijelaskan dan sumbu $Y$ menunjukkan kontribusi smoother terhadap nilai yang di uji.

Hasil uji menunjukkan parameter oseanografi yang baik atau cenderung disukai dan melimpah untuk ikan cakalang pada saat penelitian untuk klorofil-a berkisar antara 0,23 $-0,27 \mathrm{mgm}^{-3}$, dan untuk suhu permukaan laut berkisar 28,5 - 29,4 ${ }^{\circ} \mathrm{C}$. Dalam penelitian Mustasim et al., (2015) di perairan Seram Generalized Analisys Model menjelaskan bahwa nilai kisaran SPL yakni $29,50-30,00^{\circ} \mathrm{C}$ dan dalam hubungannya dengan konsentrasi klorofil-a, daerah potensial penangkapan ikan cakalang relatif lebih tinggi yaitu berada pada pada konsentrasi klorofil-a sekitar 0,10-0,15 $\mathrm{mgm}^{-3}$.

\section{Prediksi Zona Potensial Penangkapan Ikan Cakalang}

Prediksi zona potensial penangkapan ikan cakalang diperoleh dari overlay dua citra yakni klorofil-a dan suhu permukaan laut yang kemudian disatukan dan akan terbentuk satu peta baru dengan spesifik informasi mengenai daerah penangkapan produktif. Peta ini menggabungkan nilai kisaran klorofil-a dan dan suhu permukaan laut yang mendapatkan hasil tangkapan terproduktif selama penelitian yaitu pada bulan Juli - Oktober 2018.

Pada Gambar 2 terlihat bahwa prediksi keberadaan gerombolan ikan cakalang berdasarkan overlay citra klorofil-a dan suhu pada bulan Juli bepusat pada $119^{\circ} 5^{\prime} 42.704$ "BT dan $4^{\circ} 4^{\prime} 2.56 "$ LS yang berada pada perairan kota Pare-pare dan perairan kabupaten Barru. Daerah geombolan ikan cakalang pada bulan Agustus masih berada pada perairan Kota Pare-pare dan perairan Kabupaten Barru. Pada Gambar 3 terlihat bahwa pusat dari keberadaan gerombolan ikan cakalang berada pada $119^{\circ} 19^{\prime} 29.144 " B T$ ， 46'55.536"LS dan pada $118^{\circ} 56^{\prime} 10.748 " B T, 4^{\circ} 14 ' 30.234$ "LS. 


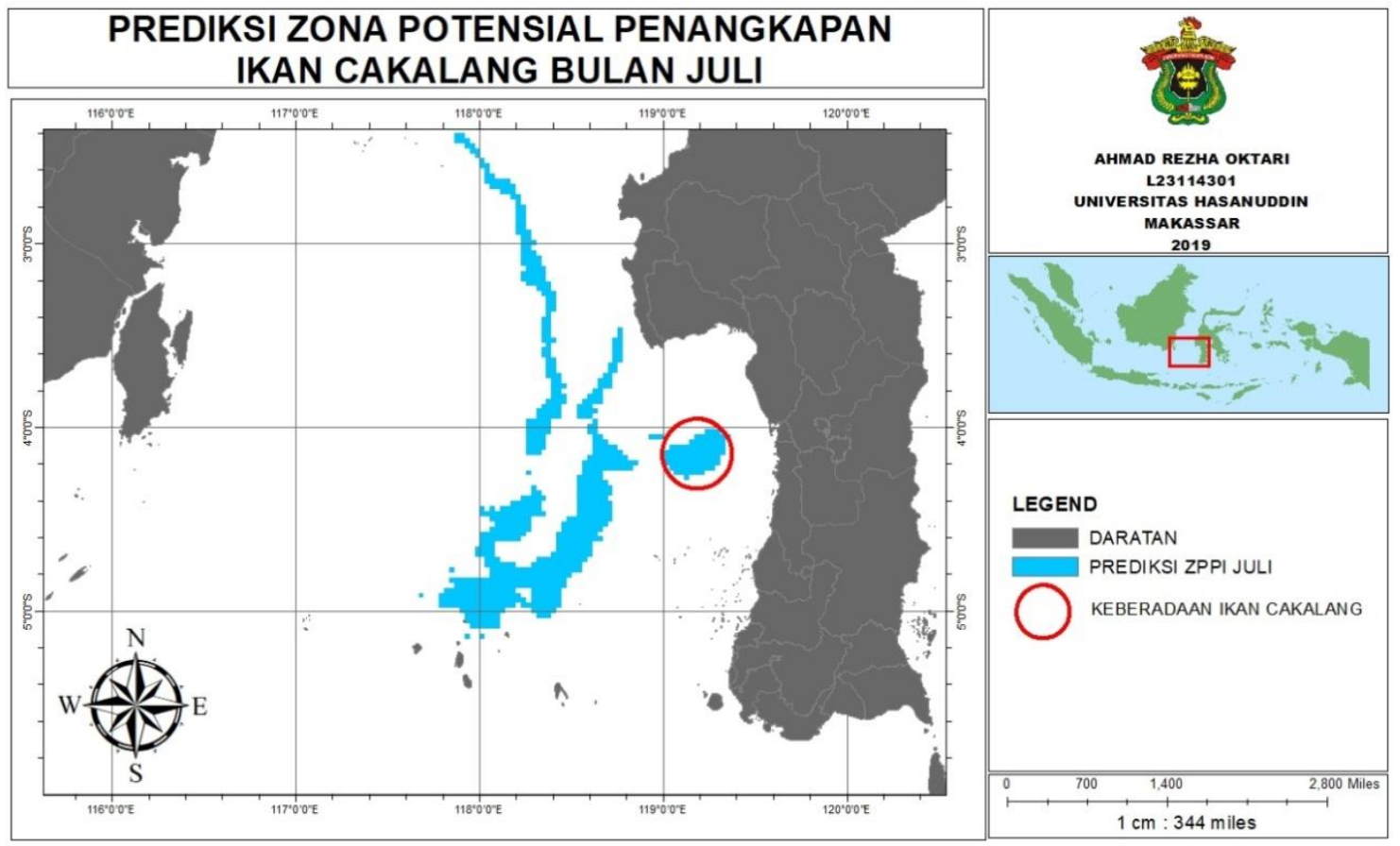

Gambar 2. Peta Prediksi Zona Potensian Penangkapan Ikan Cakalang Bulan Juli

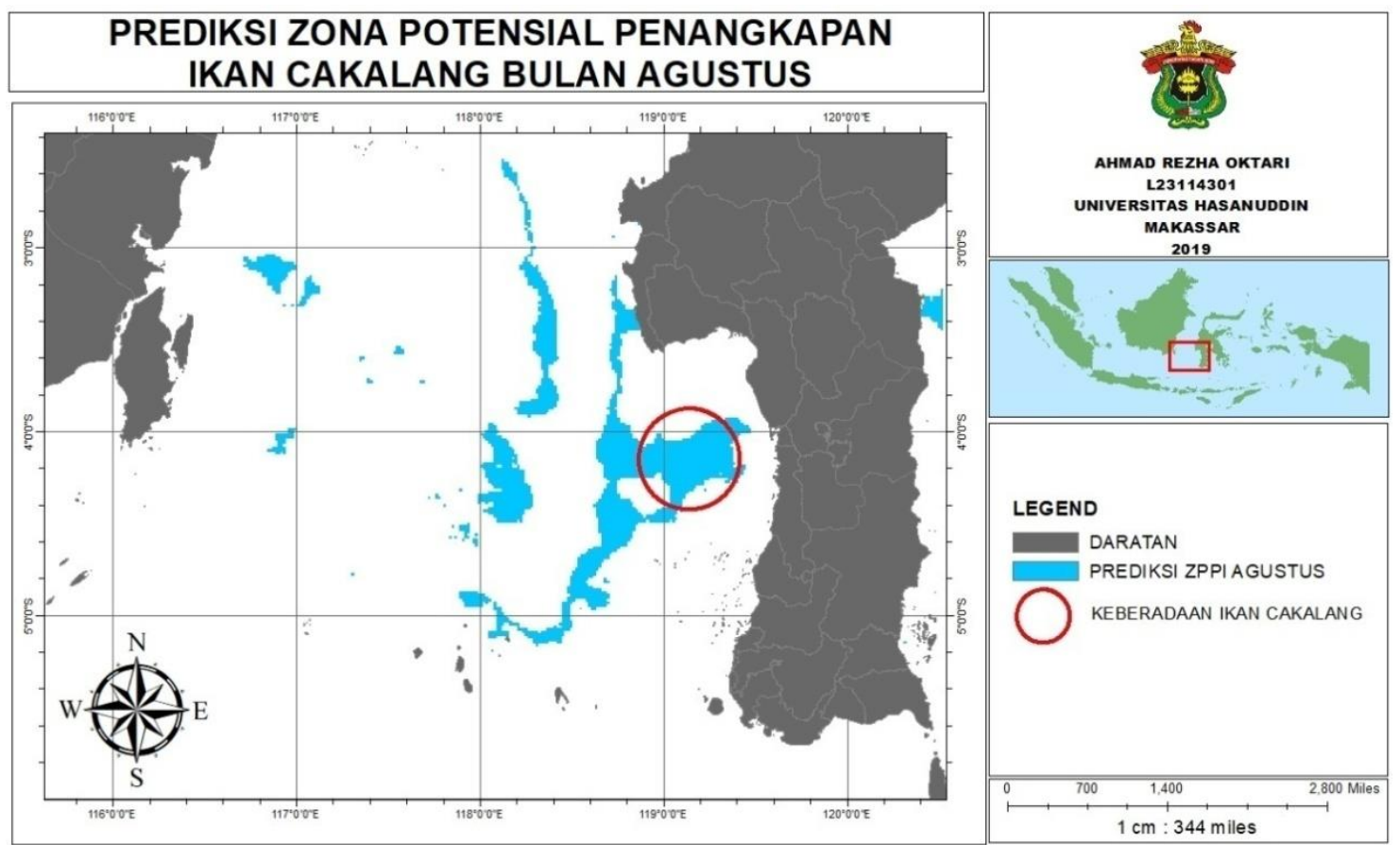

Gambar 3. Peta Prediksi Zona Potensial Penangkapan Ikan Cakalang Bulan Agustus 
Pada bulan September keberadaan ikan Cakalang dilihat pada Gambar 4 berada pada pertengahan Selat Makassar yaitu antara perairan Kabupaten Pinrang, Kota Pare-pare dan Kabupaten Barru di Sulawesi Selatan dengan perairan Kabupaten Kotabaru di Kalimantan Selatan. Pusat gerombolan ikan cakalang pada bulan September di perkirakan berada pada $117^{\circ} 53^{\prime} 49.304^{\prime \prime B T, ~ 354 ' 14.63 " L S ~}$ dan pada $117^{\circ} 43^{\prime} 31.711 " B T, 4^{\circ} 4^{\prime} 32.222 " L S$, sehingga jika dilihat dari bulan Agustus ke bulan September ikan cenderung bergerak ke arah barat.

Kemudian, dilihat pada Gambar 5 gerombolan ikan cakalang berada pada perairan Kabupaten Kotabaru, Kalimantan Selatan. Pusat gerombolan ikan cakalang pada bulan oktober diperkiran berada $116^{\circ} 50^{\prime} 43.193 " B T \quad$ dan $\quad 4^{\circ} 16^{\prime} 10.37^{\prime \prime} L S$. Pergerakan gerombolan ikan cakalang dilihat dari bulan September ke bulan Oktober juga bergerak ke arah Barat.

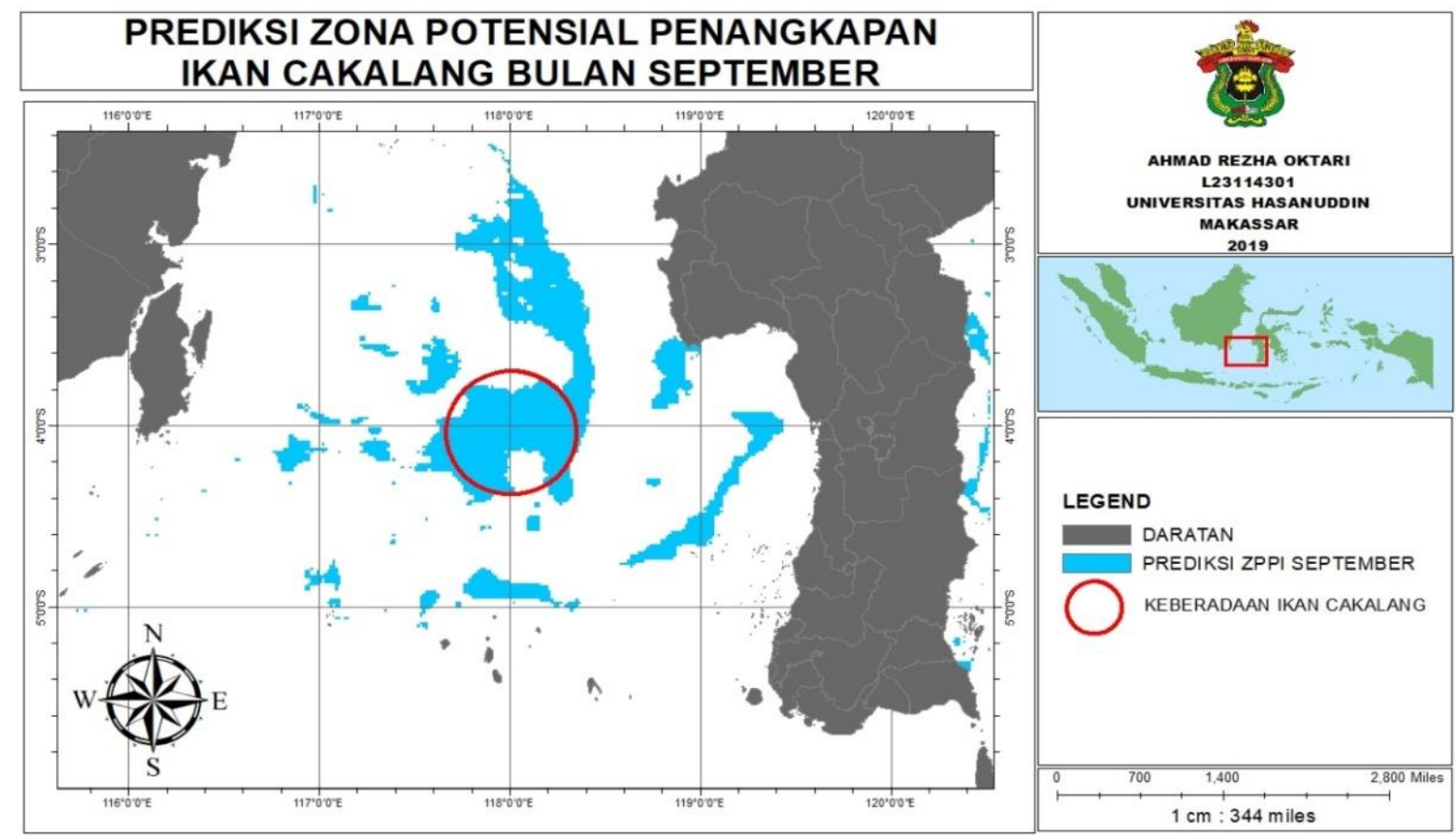

Gambar 4. Peta Prediksi Zona Potensial Penangkapan Ikan Cakalang Bulan September 


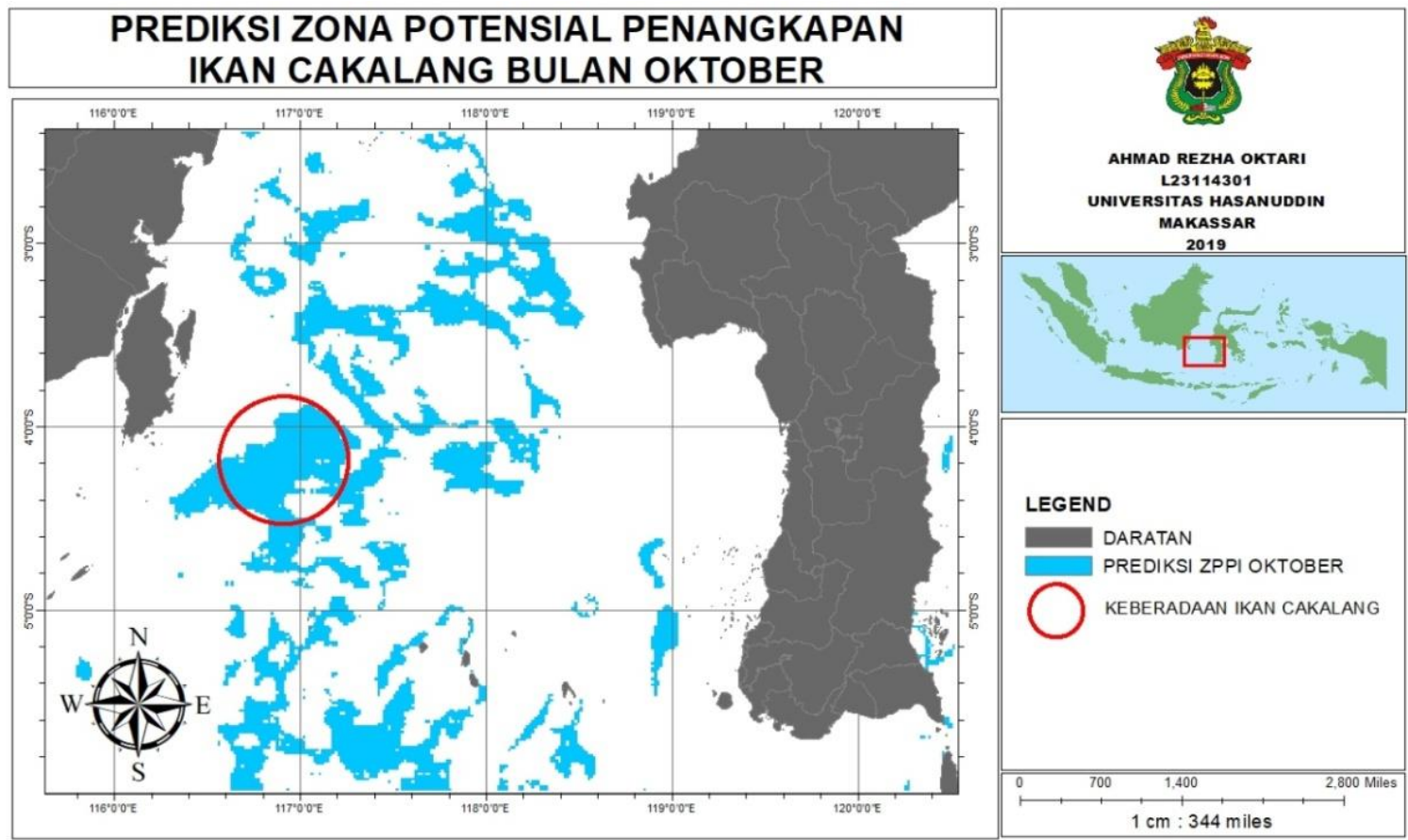

Gambar 5. Peta Prediksi Zona Potensial Penangkapan Ikan Cakalang Bulan Oktober

Dilihat dari pergerakan ikan cakalang di perairan Selat Makassar pada bulan Juli Oktober 2018, ikan cakalang bergerak ke arah barat. Terbentuknya formasi daerah penangkapan dengan menggabungkan kontur SPL dan Klorofil-a membuat proses pengambilan keputusan bagi nelayan dapat berjalan dengan tepat.Kisaran optimum dua citra tersebut dapat dijadikan sebagai kombinasi dua karakteristik habitat ikan cakalang Peta hasil overlay dua citra tersebut dapat disatukan dan akan terbentuk peta baru dengan spesifik informasi mengenai daerah penangkapan ikan yang produktif yang dikenal dengan zona optimum penangkapan ikan cakalang (Zainuddin,2011, Zainuddin et al, 2013).

Sedangkan untuk mengetahui pola pergerakan ikan cakalang bulan Juli sampai dengan bulan Oktober 2018 di Perairan Selat Makassar, maka dapat dilihat pada Gambar 6. 


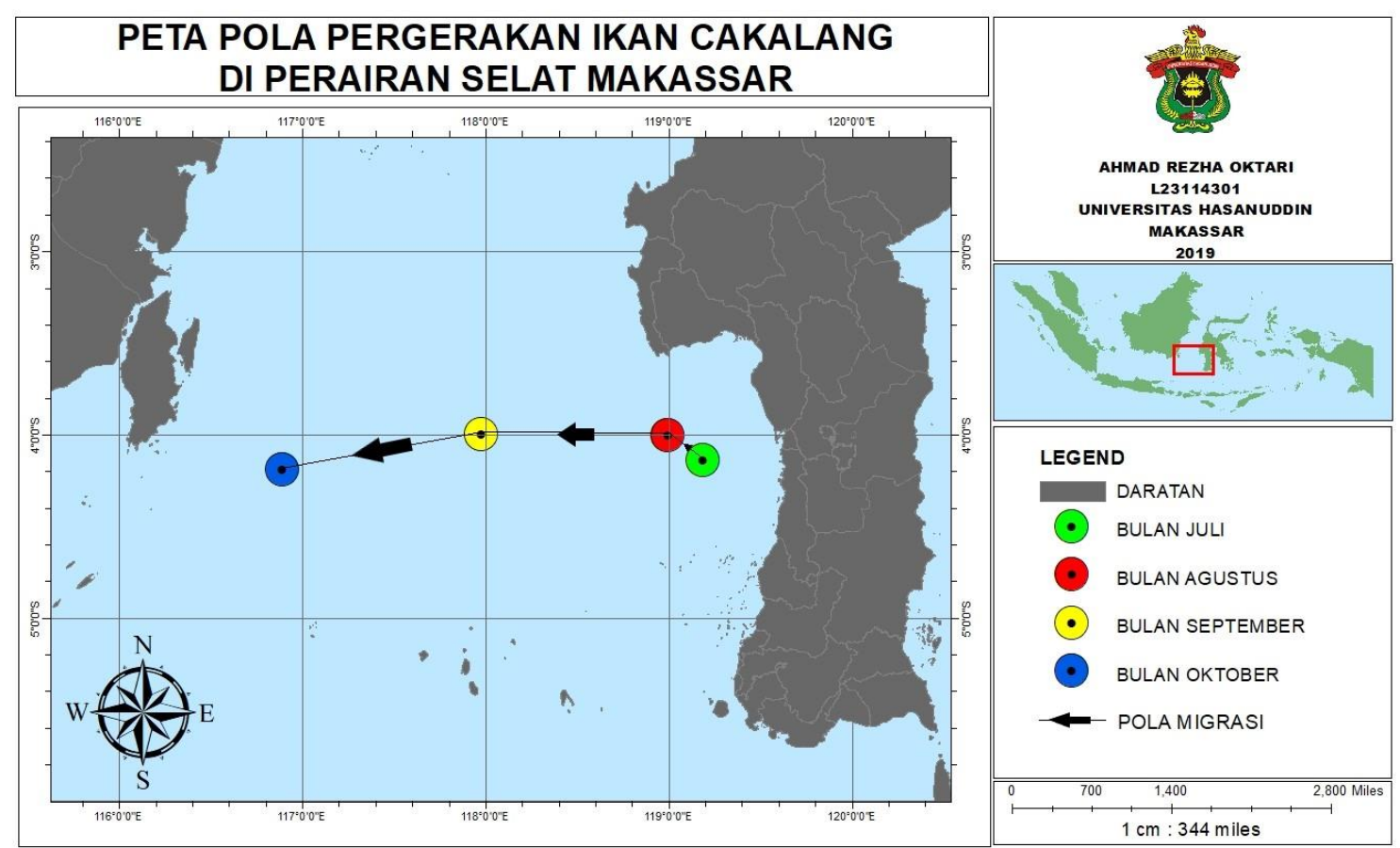

Gambar 6. Peta Pola Pergerakan Ikan Cakalang Bulan Juli-Oktober 2018

Dan berikut tabel daerah konsentrasi

ikan Cakalang pada bulan Juli sampai bulan

Oktober 2018 di Perairan Selat Makassar.

Tabel 2. Daerah Konsentrasi Ikan Cakalang pada Bulan Juli - Oktober 2018 di Perairan Selat Makassar

\begin{tabular}{|c|c|c|c|}
\hline No & Bulan & Lokasi/Posisi & Keterangan \\
\hline 1 & Juli & $119^{\circ} 5^{\prime} 42.704^{\prime \prime B T}$ dan $4^{\circ} 4^{\prime} 2.56^{\prime \prime} \mathrm{LS}$ & $\begin{array}{l}\text { Perairan kota Pare-pare dan perairan kabupaten } \\
\text { Barru }\end{array}$ \\
\hline 2 & Agustus & $\begin{array}{c}119^{\circ} 19^{\prime} 29.144^{\prime \prime B T}, 4^{\circ} 6^{\prime} 55.536 " L S \text { dan pada } \\
118^{\circ} 56^{\prime} 10.748 \text { "BT, } 4^{\circ} 14^{\prime} 30.234^{\prime L S}\end{array}$ & $\begin{array}{l}\text { Perairan Kota Pare-pare dan perairan Kabupaten } \\
\text { Barru }\end{array}$ \\
\hline 3 & Septembar & $\begin{array}{c}117^{\circ} 53^{\prime} 49.304^{\prime \prime} \mathrm{BT}, 3^{\circ} 54^{\prime} 14.63^{\prime \prime} \mathrm{LS} \text { dan pada } \\
117^{\circ} 43^{\prime} 31.711 \text { "BT, } 4^{\circ} 4^{\prime} 32.222^{\prime \prime L S}\end{array}$ & $\begin{array}{l}\text { Pertengahan selat Makassar yaitu antara perairan } \\
\text { Kabupaten Pinrang, Kota Pare-pare dan } \\
\text { Kabupaten Barru di Sulawesi Selatan dengan } \\
\text { perairan Kabupaten Kotabaru di Kalimantan } \\
\text { Selatan }\end{array}$ \\
\hline 4 & Oktober & $116^{\circ} 50^{\prime} 43.193^{\prime \prime B T}$ dan $4^{\circ} 16^{\prime} 10.37^{\prime \prime L S}$ & Perairan Kabupaten Kotabaru, Kalimantan Selatan \\
\hline
\end{tabular}

\section{KESIMPULAN}

Pola pergerakan ikan cakalang pada bulan Juli sampai Oktober dipengaruhi oleh konsentrasi Klorofil-a. Pola pergerakan ikan cakalang di Perairan Selat Makassar pada bulan Juli - Oktober 2018 berada pada Perairan Kota Pare-pare dan Kabupaten Barru,
Sulawesi Selatan sampai pada Perairan Kabupaten Kotabaru, Kalimantan Selatan.

\section{DAFTAR PUSTAKA}

Afdal \& Riyono, 2004. Sebaran Klorofil-a Kaitannya Dengan Kondisi Hidrologi Di Selat Makassar. Oseanologi dan 
Linrnologi di Indonesia No. 36:69-82. Bidang Dinamika Laut, Pusat Penelitian Oseanografi LIPI.

Amir, F \& Mallawa, A. 2015. Pengkajian Stok Ikan Cakalang (Katsuwonus pelamis) di Perairan Selat Makassar. Jurnal IPTEKS PSP. Vol.2, No.3: 208-217.

Edmondri. 1999. Studi Daerah Penangkapan Ikan Cakalang dan Madidihang di Perairan Sumatera Barat pada Musim Timur. Skripsi Sarjana. Bogor: Jurusan Pemanfaatan Sumberdaya Perikanan. Fakultas Perikanan dan Ilmu Kelautan. Institut Pertanian Bogor. 48 hal.

Effendi, R., Pariabti P \& Nasrul I. 2012. Analisis Konsentrasi Klorofil-A Di Perairan Sekitar Kota Makassar Menggunakan Data Satelit Topex/Poseidon. Jurnal Sains dan Pendidikan Fisika. Jilid 8, Nomor 3, Desember 2012, hal $279-285$.

Gordon A. 2005. The oceanography of the Indonesian Seas and Their Throughflow. Oceanography 18(4):14-27.

Inaku, D.F. 2011. Analisis Pola Sebaran Dan Perkembangan Area Upwelling Di Bagian Selatan Perairan Selat Makassar. Tesis. Bogor. Sekolah Pascasarjana, Institut Pertanian Bogor.
Mustasim, Zainuddin M \& Safruddin. 2015. Thermal dan Klorofil-a Front Hubungannya dengan Hasil Tangkapan Ikan Cakalang pada Musim Peralihan Barat - Timur di Perairan Seram. Jurnal IPTEKS PSP, Vol.2 (4) Oktober 2015: 294-304

Wibawa, Teja,A, Novianto,D , \& Nugraha, B. 2012. Sebaran Spasial Kelimpahan Ikan Cakalang (Katsuwonus pelamis) berdasarkan Analisis Data Satelit Oseanografi. Disajikan 29-30 November pada Prosiding InSINas 2012.

Zainuddin, M. 2011. Skipjack Tuna in Relation to Sea Surface Temperature ang Chlorophyll-a Concentration of Bone Bay Using Remotely Sensed Satellite Data. Jurnal Ilmu dan Teknologi Kelautan Tropis No.1 Juni 2011.

Zainuddin, M., Najamuddin., Farhum A., \& Hajar M.A.I. 2013. Characterizing Potential Fishing Zone of Skipjack Tuna During the Southeast Monsoon in Bone Bay - Flores Sea Using Remotely Sensed Oceanographic Data. International Journal of Geosciences. 4, 259-266. 